\title{
Binge eating, sociodemographic and lifestyle factors in participants of the ELSA-Brazil
}

\author{
Thamyres Souza da Silva ${ }^{1 *}$, Maria Del Carmen Bisi Molina', Maria Angélica Antunes Nunes², \\ Carolina Perim de Faria ${ }^{1}$ and Nagela Valadão Cade ${ }^{1}$
}

\begin{abstract}
Background: This study investigates the relationship between recurrent binge eating episodes and nutritional and food profiles and lifestyle in the Brazilian Longitudinal Study of Adult Health (Estudo Longitudinal da Saúde do Adulto - ELSA-Brazil) cohort.

Results: Recurrent binge eating episodes were associated with obesity (OR 5.188; confidence interval [Cl] 4.0516.645), overweight (OR 2.534; Cl 1.980-3.243), female sex (OR 1.918; Cl 1.573-2.338), age between 34 and 54 years old (OR 1.349; Cl 1.115-1.631), alcohol ingestion $\geq 5$ in two hours (OR 1.397; Cl 1.068-1.827), and insufficient physical activity (OR 1.290; Cl 1.078-1.544).
\end{abstract}

Conclusion: Being overweight has an important association with recurrent binge eating episodes, as does demographic and lifestyle characteristics, including excessive alcohol consumption.

Keywords: Binge Eating Disorder, Eating Behaviour, Lifestyle, Obesity

\section{Background}

Binge eating is a behaviour characterised by exaggerated food ingestion over a short period of time, followed by a sense of loss of control over the amounts eaten [1-4]. Binge eating behaviour occurs as a central symptom of eating disorders such as binge eating disorder (BED) bulimia nervosa and anorexia nervosa or as sporadic, a partial behavior when they do not meet all the diagnostic criteria for the disorder, but it can bring discomfort and seeking treatment because of the recurrent binge eating episodes [2, 3].

Studies performed among the Brazilian population have reported the prevalence of recurrent binge eating episodes to range from $12.8 \%$ in the general population over 18 years [5], $24.6 \%$ in teenagers, with girls presenting a higher prevalence than boys (31\%) [6] and up to $39.3 \%$ in overweight adults [7].A study performed by Hood et al. found a prevalence of recurrent binge

\footnotetext{
* Correspondence: thatasds@hotmail.com

${ }^{1}$ Federal University of Espírito Santo (Universidade Federal do Espírito Santo), Vitória, Brazil

Full list of author information is available at the end of the article
}

eating episodes of $33 \%$ among obese adults, which was similar to the Brazilian studies [8]. Although different methods of assessment have been used, generally similar prevalences of recurrent binge eating episodes are reported worldwide in obese and general population groups [9-11].

Individuals with recurrent binge eating episodes or BED present with higher levels of caloric consumption [12] and cravings (abnormal food desires) [13]. Other factors not diet-related that are associated with BED include higher alcohol consumption [6, 14], lower physical activity $[6,15]$, anxiety and depression $[16]$ and health conditions such as diabetes and hypertension [17].

The goal of the present study was to investigate the frequency of recurrent binge eating episodes and their relationship with nutritional profiles, eating profiles and selected lifestyle factors in a cohort of 15,105 public servants aged between 35 and 74 years old from the Brazilian Longitudinal Study of Adult Health (Estudo Longitudinal da Saúde do Adulto - ELSA-Brazil). The present study is important because few studies have investigated the prevalence of recurrent binge eating episodes and related risk 
factors in adult, aging populations and in the non-obese $[5,8,9,11,16,18,19]$.

\section{Method \\ Design and participants}

This cross sectional observational study used baseline data from the Brazilian Longitudinal Study of Adult Health (ELSA-Brazil) [20]. The sample consisted of 15,105 public servants from six higher education institutions, active or retired, aged between 35 and 74 years old, who participated in the first stage of data collection of ELSA-Brazil, which ended in 2010.

The outcome variable was the presence of recurrent binge eating episodes, and the exposure variables included sociodemographic (sex, age, self-reported race/ ethnicity, level of education and income per capita), nutritional (total calories and calories per food group), weight (body mass index [BMI]), and other lifestyle (smoking, alcohol and physical activity) factors. In Brazil, due to a wide variety of mixed national and ethnic groups in the population, race/ethnicity is categorised using self-reported skin color of black, brown, white, yellow (Asian) or red (indigenous).

\section{Assessments}

Recurrent binge eating episodes evaluation was based on the DSM IV [3] definition as in the following question: "Some people, in some occasions, eat large amounts of food at once, over a short period of time (up to 2 hours). They feel that they have lost control, that is, they cannot avoid starting to eat, and after they start, they cannot stop. Over the past six months, how frequently did you eat in this way?" recurrent binge eating episodes were considered present when a participant reported that this type of overeating occurred twice or more a week over the previous six months. Education was categorized according to the schooling level: first degree or fundamental (primary) up to nine years of study, high school up to 12 years of study and college (university) over 12 years of study, and monthly income and income per capita, calculated based on the value of minimum wage at the time of the study.

Food consumption data were collected using the Food Frequency Questionnaire (FFQ. This semi-quantitative tool includes 114 items and focuses on the usual ingestion profile over the last twelve months [21].

Energy consumption was evaluated using Nutrition Data System for Research (NDRS) software. Overestimation due to self-referring was corrected by adjusting the value to the 99 percentile, and when seasonal food consumption was observed, the total value of daily consumption was multiplied by 0.25 .

Alcohol consumption (in grams of ethanol) data were obtained from the FFQ; it was also assessed by a specific questionnaire that focused on drinking habits and the frequency of consumption of five or more drinks of any kind in periods of two hours regardless of the frequency, suggests episodes of compulsive drinking [22].

Smoking was evaluated using a semi-structured questionnaire with questions about smoking habits at the time of the interview, in the past, or whether the participant had never smoked [19]. Physical activity was evaluated using the International Physical Activity Questionnaire (IPAQ) [23], with previous validity having been demonstrated [24].

Activity levels took account of the sum of the activities related to leisure and commuting, as currently recommended [25].

Height and weight were measured using a stadiometer (SECA-SE-216) with a $0.1 \mathrm{~cm}$ scale and an electronic scale (Toledo 2096 PP, measures up to $200 \mathrm{~kg}$ ). BMI was calculated from the height and weight values, with these measurements taken with participants dressed in standard clothes and without shoes or glasses [26]. The BMI cut-off points proposed by the World Health Organization (2000) were used as a reference [27].

All data were collected by personnel trained and certified for the use of standardised ELSA protocols, face-toface interview questionnaires, and benchmarking.

\section{Statistical analysis}

Categorical variables were compared using the Chi-square test, Fisher's exact test, or the maximum likelihood ratio. Differences between groups of non-parametric continuous data were tested using the Mann-Whitney $U$ test. Thereafter logistic regression was performed to identify significant univariate factors uniquely associated with recurrent binge eating episodes. Results of the bivariate analysis were used to determine which variables were inserted on the final model.

Odds ratios (OR) with a $95 \%$ confidence interval (CI) were calculated. All analyses were performed using SPSS 15.0 software, with significance set at $p<0.05$.

\section{Ethics}

Because this study was a multicentre study, the ELSABrazil project was approved by the Research Ethics National Committee (Comitê Nacional de Ética em Pesquisa) and by the committees of each institution involved in December 2008 (Study registration number $=140 / 08$ ).

\section{Results}

Among the 15,074 participants $(99.9 \%$ of the ELSABrazil) who answered the question regarding compulsion, 980 (6.5 \%; 95 \% CI 6.1-6.9 \%) participants reported binge eating episodes twice or more than twice a week, and comprised the sample of participants with recurrent binge eating episodes in this study. Of those with recurrent binge eating episodes $66.6 \%$ were women, $68.2 \%$ were in 
Table 1 Sociodemographic, nutritional, and life style characterisation, according to the presence of recurrent binge eating episodes, in the ELSA-Brazil $(N=15,105)$

\begin{tabular}{|c|c|c|c|c|c|}
\hline \multirow[t]{3}{*}{ Variables } & \multicolumn{4}{|c|}{$\begin{array}{l}\text { Recurrent binge } \\
\text { eating episodes }\end{array}$} & \multirow[t]{3}{*}{$p$-value } \\
\hline & \multicolumn{2}{|l|}{ Yes } & \multicolumn{2}{|l|}{ No } & \\
\hline & $\bar{n}$ & $\%$ & $n$ & $\%$ & \\
\hline \multicolumn{6}{|l|}{ Sex } \\
\hline Male & 327 & 33.4 & 6548 & 45.6 & \\
\hline Female & 653 & 66.6 & 7546 & 54.4 & 0.000 \\
\hline Total & 980 & & 14,094 & & \\
\hline \multicolumn{6}{|l|}{ Age } \\
\hline 34 to 54 years old & 668 & 68.2 & 8597 & 61.0 & \\
\hline 55 to 75 years old & 312 & 31.8 & 5497 & 39.0 & 0.000 \\
\hline Total & 980 & & 14,094 & & \\
\hline \multicolumn{6}{|l|}{ Colour or race } \\
\hline Black & 183 & 18.7 & 2211 & 15.7 & \\
\hline Brown & 298 & 30.4 & 3898 & 27.7 & \\
\hline White & 447 & 45.6 & 7338 & 52.1 & 0.000 \\
\hline Asian & 21 & 2.1 & 352 & 2.5 & \\
\hline Indigenous & 19 & 1.9 & 138 & 1.0 & \\
\hline Total & 968 & & 13,937 & & \\
\hline \multicolumn{6}{|l|}{ Education level } \\
\hline $\begin{array}{l}\text { Incomplete primary } \\
\text { school }\end{array}$ & 70 & 7.1 & 817 & 5.8 & \\
\hline $\begin{array}{l}\text { Complete primary } \\
\text { school/incomplete } \\
\text { secondary school }\end{array}$ & 72 & 7.3 & 952 & 6.8 & 0.003 \\
\hline $\begin{array}{l}\text { Complete secondary } \\
\text { school/Incomplete } \\
\text { university }\end{array}$ & 377 & 38.5 & 4846 & 34.4 & \\
\hline University or Graduate & 461 & 47.0 & 7479 & 53.1 & \\
\hline Total & 980 & & 14,094 & & \\
\hline \multicolumn{6}{|l|}{ BMl } \\
\hline Thin; $<18.5$ & 1 & 0.1 & 140 & 1.0 & \\
\hline Eutrophic: 18.5-24.99 & 144 & 14.7 & 5264 & 37.3 & \\
\hline Overweight: 25-29.99 & 385 & 39.3 & 5681 & 40.3 & 0.000 \\
\hline Obese: $\geq 30$ & 450 & 45.9 & 3003 & 21.3 & \\
\hline Total & 980 & & 14,088 & & \\
\hline \multicolumn{6}{|l|}{ Physical activity } \\
\hline Insufficiently active & 633 & 64.6 & 7500 & 53.2 & \\
\hline Sufficiently active & 347 & 53.4 & 6594 & 46.8 & 0.000 \\
\hline Total & 980 & & 14,094 & & \\
\hline \multicolumn{6}{|l|}{ Smoking } \\
\hline Never smoked & 528 & 53.9 & 8055 & 57.2 & \\
\hline Ex-smoker & 322 & 32.9 & 4197 & 29.8 & 0.098 \\
\hline Smoker & 130 & 13.3 & 1841 & 13.1 & \\
\hline Total & 980 & & 14,093 & & \\
\hline
\end{tabular}

Table 1 Sociodemographic, nutritional, and life style characterisation, according to the presence of recurrent binge eating episodes, in the ELSA-Brazil $(N=15,105)$ (Continued)

Alcohol intake $\geq 5$ standard units

of alcohol in $2 \mathrm{~h}$

\begin{tabular}{lllll} 
Twice a day or more & 6 & 33 & 0.2 & \\
Practically every day & 3 & 111 & 0.8 & \\
Once or twice a week & 87 & 1072 & 7.6 & \\
Twice or three times a month & 43 & 637 & 4.5 & 0.002 \\
Only on special occasions & 236 & 3872 & 27.5 & \\
Never & 222 & 4103 & 29.1 & \\
Total & 980 & 14.094 & & \\
\hline
\end{tabular}

the younger age category, $18.7 \%$ were of black and $30.4 \%$ of brown race/colour and $52.9 \%$ did not have university education. Participants with recurrent binge eating episodes were much more likely to be obese ( $45.9 \%$ ), to be less active $(64.6 \%)$ and to have patterns of high alcohol ingestion over short periods of time, once or twice a week (8.9\%) (Table 1).

Analysis found calorie consumption was associated with weight gain (BMI). Calorie consumption was higher for participants presenting with recurrent binge eating episodes, independent of BMI (Table 2). Participants presenting with recurrent binge eating episodes also exhibited higher consumption levels in all food groups, except for group 3, vegetables and legumes, and group 8 , alcoholic beverages (Table 3 ).

Logistic regression analysis indicated that obese individuals presented an almost 5.2 times higher risk of binge eating episodes; overweight individuals presented a 2.5 times higher risk (Table 4). Higher recurrent binge eating episodes probabilities were present for women (1.9 times higher), individuals between 34 and 54 years old (1.4 times higher), those with alcohol ingestion higher or equal to five standard units of alcohol in two hours (1.4 times higher), and those who were insufficiently physically active (1.3 times higher).

\section{Discussion}

The prevalence of recurrent binge eating episodes in this study was $6.5 \%$ and was lower than that of an earlier national study that found a prevalence of $12.8 \%$ among adults from five Brazilian regional capitals. This difference in prevalence may be due the characteristics of the samples because the present study used a greater demographic cross-section of adults.

The results of this study indicated that being female, younger, overweight (overweight and obesity) and insufficiently physically active and using alcohol with a compulsive pattern contributed more to the occurrence of binge eating episodes. These findings are in accordance with 
Table 2 Distribution of ingested calories per BMl, depending on the presence or absence of recurrent binge eating episodes, in the ELSA-Brazil $(n=15,105)$

\begin{tabular}{llllllll}
\hline BMl & Binge eating & $n$ & Lowest Value & Highest Value & Median & Mean & Standard deviation \\
\hline Underweight; $<18.5^{\text {a }}$ & Yes & 1 & n.a. & n.a. & $2139.05^{\text {b }}$ & n.a. & n.a. \\
& No & 140 & 1093.82 & 9550.04 & 2814.09 & 3182.89 & 1426.44 \\
Eutrophic: $18.5-24.99$ & Yes & 144 & 1080.55 & 15395.60 & 2849.63 & 3234.28 & 1644.59 \\
& No & 5259 & 489.71 & 15344.07 & 2648.90 & 2906.87 & 1207.48 \\
Overweight:25-29.99 & Yes & 385 & 932.76 & 11673.80 & 2918.77 & 3195.73 & 1374.26 \\
& No & 5674 & 345.02 & 14014.68 & 2723.82 & 2959.58 & 1218.13 \\
Obesity: 230 & Yes & 450 & 961.50 & 11536.98 & 3200.46 & 3438.64 & 1380.27 \\
& No & 3002 & 294.02 & 11146.48 & 2744.69 & 2988.47 & 1231.65 \\
\hline
\end{tabular}

${ }^{\mathrm{a}}$ For the thin group, it was not possible to compare it with the different groups. ${ }^{\mathrm{b}}$ Single value

previous studies [6, 28-33], despite differing demographic features (i.e., public servants, adults and elderly individuals, mostly with completed secondary school educations and specialised occupations).

Although few epidemiological studies describe binge eating in population representative samples, women present a higher probability of experiencing recurrent binge-eating episodes than men [28-30, 33], and is more frequent in teenagers and young adults [12, 29, 34-36]. Women and young adults may be more predisposed to recurrent binge-eating episodes and BED due to internalisation of the thin ideal [37] through which women experience overvaluation of standards of body aesthetics and weight which then can lead to eating behaviours and habits that are harmful to their health [38]. The findings are also consistent with others that have reported increases in energy intake due to high consumption of fat and sugar rich foods resulting in overweight, or decreases in daily caloric ingestion from excessive worrying about maintaining a slim and thin body in young people. Both of these may be pathways to eating disorders [39].

In this study overweight, expressed as obesity and overweight, was more strongly associated with recurrent binge eating episodes. This finding is also in accordance with previous studies that have reported that obese people to be more vulnerable to prejudice and social discrimination, which generates psychological suffering and can lead to the

Table 3 Descriptive analysis of food consumption per calories, according to the presence of recurrent binge eating episodes, in the ELSA-Brazil $(n=15,105)$

\begin{tabular}{|c|c|c|c|c|c|}
\hline Variables & BED & Median & Mean & Standard deviation & $p$-value* \\
\hline \multirow[t]{2}{*}{ G1: Bread, cereal and tubers } & Yes & 450.52 & 550.49 & 395.98 & 0.000 \\
\hline & No & 370.80 & 449.99 & 323.59 & \\
\hline \multirow[t]{2}{*}{ G2: Fruit } & Yes & 271.25 & 348.67 & 294.60 & 0.014 \\
\hline & No & 255.33 & 317.16 & 251.26 & \\
\hline \multirow[t]{2}{*}{ G3: Vegetables and legumes } & Yes & 0.00 & 32.12 & 74.62 & 0.001 \\
\hline & No & 9.18 & 35.40 & 75.46 & \\
\hline \multirow[t]{2}{*}{ G4: Eggs, meat, milk and derivatives } & Yes & 181.84 & 237.92 & 202.92 & 0.000 \\
\hline & No & 162.13 & 205.06 & 169.07 & \\
\hline \multirow[t]{2}{*}{ G5: Pasta and other prepared foods } & Yes & 165.32 & 198.17 & 147.71 & 0.000 \\
\hline & No & 143.78 & 172.72 & 125.57 & \\
\hline \multirow[t]{2}{*}{ G6: Sweets } & Yes & 88.09 & 135.69 & 143.32 & 0.000 \\
\hline & No & 72.80 & 108.93 & 117.38 & \\
\hline \multirow[t]{2}{*}{ G7: Non-alcoholic beverages } & Yes & 140.36 & 203.74 & 214.30 & 0.937 \\
\hline & No & 140.27 & 195.52 & 194.25 & \\
\hline \multirow[t]{2}{*}{ G8: Alcoholic beverages } & Yes & 8.93 & 56.04 & 119.77 & 0.000 \\
\hline & No & 17.18 & 62.70 & 114.14 & \\
\hline \multirow[t]{2}{*}{ Total calories } & Yes & 3025.08 & 3311.86 & 1422.88 & 0.000 \\
\hline & No & 2704.82 & 2946.68 & 1221.28 & \\
\hline
\end{tabular}

* Mann-Whitney test 
Table 4 Odds ratio adjusted by the multivariate logistic regression model of lifestyle and demographic exposure variables with outcome variable recurrent binge eating episodes $(n=15,105)$

\begin{tabular}{|c|c|c|c|}
\hline \multirow[t]{2}{*}{ Exposure variables } & \multicolumn{3}{|c|}{ Multivariate analysis } \\
\hline & $p$-value & OR & Cl $95 \%$ \\
\hline \multicolumn{4}{|l|}{ Gender } \\
\hline Male & & 1.000 & - \\
\hline Female & 0.000 & 1.918 & $1.573-2.338$ \\
\hline \multicolumn{4}{|l|}{ Age } \\
\hline 34 to 54 years old & 0.002 & 1.349 & $1.115-1.631$ \\
\hline 55 to 75 years old & & 1.000 & - \\
\hline \multicolumn{4}{|l|}{ BMI } \\
\hline Eutrophic & & 1.000 & - \\
\hline Thin & 0.387 & 0.416 & $0.057-3.034$ \\
\hline Overweight & 0.000 & 2.534 & $1.980-3.243$ \\
\hline Obese & 0.000 & 5.188 & $4.051-6.645$ \\
\hline \multicolumn{4}{|l|}{ Physical activity } \\
\hline Insufficiently active & 0.005 & 1.290 & $1.078-1.544$ \\
\hline Sufficiently active & & 1.000 & - \\
\hline \multicolumn{4}{|c|}{ Alcohol intake $\geq 5$ standard units of alcohol in $2 \mathrm{~h}$} \\
\hline Less frequent & & 1.000 & - \\
\hline More frequent & 0.015 & 1.397 & $1.068-1.827$ \\
\hline \multicolumn{4}{|l|}{ Calorie consumption } \\
\hline Calories Group 1 & 0.051 & 1.00036 & $0.999-1.001$ \\
\hline Calories Group 2 & 0.682 & 1.00009 & $0.99967-1.00050$ \\
\hline Calories Group 3 & 0.528 & 0.99961 & $0.99841-1.00082$ \\
\hline Calories Group 4 & 0.868 & 1.00005 & $0.99951-1.00058$ \\
\hline Calories Group 5 & 0.281 & 1.00041 & $0.99966-1.00116$ \\
\hline Calories Group 6 & 0.397 & 1.00031 & $0.99959-1.00104$ \\
\hline Calories Group 8 & 0.555 & 0.99976 & $0.99895-1.00056$ \\
\hline Total calories & 0.067 & 1.00012 & $0.99999-1.00026$ \\
\hline
\end{tabular}

use of food as a compensation for problems and frustrations [40-42]. Likewise, obese individuals may isolate themselves because they feel rejected and have difficulties in obtaining pleasure from social relations. These feelings contribute to the observation that obese individuals may consider food and overeating an important source of pleasure, but which makes their affective and social relationships harder to maintain [36]. A self-perpetuating cycle of binge eating leading to higher energy consumption and increased weight, and an imbalance between energy intake and expenditure through physical activity, and adverse consequences for interpersonal function and mood can result.

Individuals with recurrent binge eating episodes presented higher caloric consumption levels from almost all food groups except for the groups of vegetables and legumes and alcoholic beverages, but recurrent binge eating episodes was not associated with over consumption on regression analyses controlling for demographic and other lifestyle variables. Although participants with recurrent binge eating episodes ingested less alcohol than those who did not have recurrent binge eating episodes, bingedrinking over a two-hour period was higher for the recurrent binge eating episode group (five or more standard units of alcohol for men and four or more for women) [3]. Previous studies have confirmed this pattern of alcohol ingestion in people presenting binge eating episodes or BED among university women [43], teenagers [6] and obese women [13]. The fact that alcohol consumption per calorie was lower for subjects with recurrent binge eating episodes may be due to an underestimation of the consumed volume by problem-drinkers or the fact that heavy drinkers have more difficulty to evaluate alcohol consumption [44, 45]. Disordered eating may be associated with alcohol abuse due to shared factors such as lack of self-control, co-morbidities such as anxiety and depression, biological predisposition for the use of psychoactive substances [40], and dissatisfaction with body image and frustrated attempts in controlling weight, which in turn could lead to excessive food and drink consumption [46].

\section{Strengths and limitations}

A limitation in the present study is the inherent problem of comparing its findings with a literature that uses wideranging methodologies and samples to evaluate binge eating and food consumption. Due to the cross-sectional design, causal relationships could not be evaluated. Finally, limitations in assessment of caloric consumption with the FFQ need to be acknowledged. Although, total caloric consumption was high for recurrent binge eating episodes and non-recurrent binge eating episodes groups, the FFQ evaluates the usual consumption over the last twelve months and may be associated with over (or under) estimation of consumption due to variable perception of the portions being shown, reliance on memory recall, and interviewer skills [47].

\section{Conclusion}

In this study, recurrent binge eating episodes were common and was associated with being overweight and/or frankly obese, and a compulsive pattern of alcohol consumption. Further studies are needed to investigate the complex and multidimensional phenomena of binge eating and its associated health consequences including obesity.

\section{Authors' contributions}

All authors read and approved the final manuscript.

Competing interests

The authors declare that they have no competing interests. 


\section{Author details}

'Federal University of Espírito Santo (Universidade Federal do Espírito Santo), Vitória, Brazil. ${ }^{2}$ Federal University of Rio Grande do Sul (Universidade Federal do Rio Grande do Sul), Porto Alegre, Brazil.

\section{Received: 14 July 2014 Accepted: 18 February 2016}

Published online: 27 October 2016

\section{References}

1. Wermuth BM et al. Phenytoin treatment of the binge eating syndrome. Am J Psychiatry. 1977;11(12):49-53.

2. Organização Mundial da Saúde (WHO). Classificação de transtornos mentais e de comportamento da CID-10: descrições clínicas e diretrizes diagnósticas. Porto Alegre: Artes Médicas; 1993.

3. American Psychiatric Association. Diagnostic and statistical manual of mental disorders. 4th ed. Washington. D.C.: American Psychiatric Association; 1994.

4. Appolinario JC. Transtorno da compulsão alimentar periódica: uma entidade clínica emergente que responde ao tratamento farmacológico. Rev Bras Psiquiatr. 2004:26(2):75-6.

5. Siqueira KS, Appolinario JC, Sichieri R. Relationship between binge-eating episodes and self-perception of body weight in a nonclinical sample of five Brazilian cities. Rev Bras Psiquiatr. 2005;27(4):290-4.

6. Piveta LA, Silva RMVG. Compulsão alimentar e fatores associados em adolescentes de Cuiabá, Mato Grosso, Brasil. Cad Saude Publica. 2010;26(2): 337-46.

7. Vitolo MR, Bortolini GA, Horta RL. Prevalência de compulsão alimentar entre universitárias de diferentes áreas de estudo. Rev psiquiatr Rio Gd Sul. 2006; 28(1):20-6.

8. Hood MM, Grupski AE, Hall BJ, Ivan I, Corsica J. Factor structure and predictive utility of the Binge Eating Scale in bariatric surgery candidates. Surg Obes Relat Dis. 2013;9(6):942-8.

9. Prisco APK, Araújo TM, Almeida MMG, Santos KOB. Prevalência de transtornos alimentares em trabalhadores urbanos de município do Nordeste do Brasil. Ciênc saúde coletiva. 2013;18(4):1109-18.

10. Matos MIR, Aranha LS, Faria AN, Ferreira SR, Bacaltchuck J, Zanella MT. Binge eating disorder, anxiety, depression and body image in grade III obesity patients. Rev Bras Psiquiatr São Paulo. 2002;24(4):165-9.

11. Grucza RA, Przybeck TR, Cloninger R. Prevalence and correlates of binge eating disorder in a community sample. Compr Psychiatry. 2007;48(2):124-31.

12. Bartholome LT, Peterson RE, Raatz SK, Raymond NC. A comparison of the accuracy of self-reported intake with measured intake of a laboratory overeating episode in overweight and obese women with and without binge eating disorder. Eur J Nutr. 2013;52(1):193-202.

13. $\mathrm{Ng} L$, Davis $C$. Cravings and food consumption in binge eating disorder. Eat Behav. 2013;14(4):472-5.

14. Piran N, Gadalla T. Eating disorders and substance abuse in Canadian women: a national study. Addiction. 2007;102(4):105-13.

15. Deboer LB, Candyce DT, Katherine EP, Mark BP, Austin SB, Jasper SAJ. Physical activity as a moderator of the association between anxiety sensitivity and binge eating. Eat Behav. 2012;13(3):194-201.

16. Pokrajac-Buliana A, Tkalcica M, Randic NA. Binge eating as a determinant of emotional state in overweight and obese males with cardiovascular disease. Maturitas. 2013;74(4):352-6.

17. Kessler RC, Berglund PA, Chiu WT, Deitz AC, Hudson Jl, Shahly V, et al. The prevalence and correlates of binge eating disorder in the World Health Organization World Mental Health Surveys. Biol Psychiatry. 2013; 73(9):904-14

18. Freitas SR. Prevalence of BE and associated factors in a Brazilian probability sample of midlife women. Int J Eat Disord. 2008;41(5):471-8.

19. Mosca LN, Costa LRLG, Ramos CFC, Asano LMT, Ferreira AD. Compulsão alimentar periódica de pacientes em tratamento para redução de peso. J Health Sci Inst. 2010;28(1):59-63.

20. Aquino EM, Barreto SM, Benseñor IM, Carvalho MS, Chor D, Duncan BB, et al. Brazilian Longitudinal Study of Adult Health (ELSA-Brasil): Objectives and Design. Am J Epidemiology. 2012;175(4):315-24.

21. Molina MCB, Benseñor IM, Cardoso LO, Velasquez-Melendez G, Drehme M, Pereira TS, et al. Reprodutibilidade e validade relativa do Questionário de Frequência Alimentar do ELSA-Brasil. Cad Saude Publica. 2013;29(2): 379-89.
22. Stickley A, Koyanagi A, Koposov R, Razvodovsky Y, Ruchkin V. Adolescent binge drinking and risky health behaviours: Findings from northern Russia. Drug Alcohol Depend. 2013;133(3):838-44.

23. Ministério da Saúde do Brasil. Instituto Nacional do Câncer - INCA Coordenação de prevenção e Vigilância (CONPREV). Abordagem e tratamento do fumante: consenso 2001. Rio de Janeiro: INCA; 2001.

24. Matsudo SM, Araújo T, Marsudo V, Andrade D, Andrade E, Oliveira LC, et al. Questionário Internacional de Atividade Física (IPAQ): estudo de validade e reprodutibilidade no Brasil. Rev Bras Ativ Fís Saúd. 2001;6(2):05-18.

25. Hallal PC, Gomez LF, Parra DC, Lobelo F, Mosquera J, Florindo AA, et al. Lessons learned after 10 years of IPAQ use in Brazil and Colombia. J Physical Activity Health. 2010;7(2):259-64.

26. Mill JG, Pinto K, Griep RH, Goulart A, Foppa M, Lotufo PA. Aferições e exames clínicos realizados nos participantes do ELSA-Brasil. Rev Saude Publica. 2013:47(2):54-62.

27. WHO - World Health Organization. Obesity: preventing and managing the global epidemic: Technical Report of a WHO Expert Consultation on Obesity. WHO. 2000

28. Cremonini F, Camilleri M, Clark MM, Beebe TJ, Locke GR, Zinsmeister AR, et al. Associations among binge eating behavior patterns and gastrointestinal symptoms: a population-based study. Int J Obes (Lond). 2009:33(3):342-53.

29. Didie ER, Fitzgibbon M. Binge eating and psychological distress: Is the degree of obesity a factor? Eat Behav. 2005;6(1):35-41.

30. Ferreira JES, Veiga GV. Eating disorder risk behavior in Brazilian adolescents from low socio-economic level. Appetite. 2008;51(2):249-55.

31. Burmeister JM, Carels RA. Television use and binge eating in adults seeking weight loss treatment. Eat Behav. 2014;15(1):83-6.

32. Lo Coco G, Salerno L, Bruno V, Caltabiano ML, Ricciardelli LA. Binge eating partially mediates the relationship between body image dissatisfaction and psychological distress in obese treatment seeking individuals. Eat Behav. 2014;15(1):45-8

33. Lundgren JD, Rempfer MV, Brown CE, Goetz J, Hamara E, et al. The prevalence of night eating syndrome and binge eating disorder among overweight and obese individuals with serious mental illness. Psychiatry Res. 2010;175(3):233-6.

34. Elliott CA, Tanofsky-kraff M, Mirza NM. Parent report of binge eating in Hispanic, African American and Caucasian youth. Eat Behav. 2013;14(1):1-6.

35. Johnson WG, Rohan KJ, Kirk AA. Prevalence and correlates of binge eating in white and African American adolescents. Eat Behav. 2002:3(2):179-89.

36. Napolitano MA, Himes S. Race, weight, and correlates of binge eating in female college students. Eat Behav. 2011;12(1):29-36.

37. Paxton SJ, Eisenberg ME, Neumark-Sztainer D. Prospective predictors of body dissatisfaction in adolescent girls and boys: a five-year longitudinal study. Dev Psychol. 2006;42(5):888-99.

38. Kakeshita IS, Almeida SS. Relação entre índice de massa corporal e a percepção da auto-imagem em universitários. Rev Saude Publica. 2006; 40(3):497-504.

39. Serra GMA, Santos EM. Saúde e mídia na construção da obesidade e do corpo perfeito. Cien Saude Colet. 2003:8(3):691-701.

40. Peat CM, Huang L, Thornton LM, Von Holle AF, Trace SE, Lichtenstein P, et al. Binge eating, body mass index, and gastrointestinal symptoms. J Psychosom Res. 2013;75(5):456-61.

41. Bernardi F, Cichelero C, Vitolo MR. Comportamento de Restrição Alimentar e obesidade. Rev Nutr Campinas. 2005;18(1):85-93.

42. Canetti L, Bachar E, Berry EM. Food and emotion. Behav Processes. 2002 60(2):157-64.

43. Luce KH, Engler PA, Crowther JH. Eating disorders and alcohol use: Group differences in consumption rates and drinking motives. Eat Behav. 2007;8(2): $177-84$

44. National Institute of Alcohol Abuse and Alcoholism Council approves definition of binge drinking. NIAAA Newsletter.fev. 2004. Disponível em: http://pubs.niaaa.nih.gov/publications/Newsletter/winter2004/Newsletter_ Number3.htm. Accessed 5 Dec 2013.

45. Hart CL, Smith GD, Gruer L, Watt GCM. The combined effect of smoking tobacco and drinking alcohol on cause-specific mortality: a 30 year cohort study. BMC Public Health. 2010;10:789-92.

46. Krahn DD. The relationship of eating disorders and substance abuse. J Subst Abuse. 1991:3(1):239-53.

47. Willet WC. Nutritional Epidemiology. 2nd ed. New York: Oxford University Press; 1998. 